\title{
The Influence of Demographic Characteristics on Employee Promotion: Research Based on Data Mining and Game Theory
}

\author{
Chang Zhang, ${ }^{1,2}$ Ting-jie Lv, ${ }^{1}$ Chun-hui Yuan $\mathbb{D}^{1},{ }^{1}$ Yuan-yuan Ren, ${ }^{2}$ and Shuo Wang ${ }^{2}$ \\ ${ }^{1}$ School of Economics and Management, Beijing University of Posts and Telecommunications, Beijing 100876, China \\ ${ }^{2}$ Shi Jiazhuang Posts and Telecommunications Technical College, Shijiazhuang 050021, China \\ Correspondence should be addressed to Chun-hui Yuan; yuanchunhui@139.com
}

Received 17 June 2020; Revised 28 July 2020; Accepted 24 August 2020; Published 24 September 2020

Academic Editor: Wei Wang

Copyright (C) 2020 Chang Zhang et al. This is an open access article distributed under the Creative Commons Attribution License, which permits unrestricted use, distribution, and reproduction in any medium, provided the original work is properly cited.

\begin{abstract}
The motivation of the paper is to find out the influence of demographic characteristic factors on employees' career promotion in China's state-owned enterprises and study the relationship between promotion mechanism and enterprise benefits. More than 6,500 pieces of human resource data from China's state-owned enterprises were studied. Logistic regression is adopted to analyze the correlation between demographic characteristics and promotion. Meanwhile, different data mining methods are used to summarize the characteristics of promotion. On this basis, this study uses the principal-agent model of game theory to analyze the profits of employees and enterprises under different promotion mechanisms and demonstrates the conditions for enterprises to obtain the maximum benefit from the employees' promotion. The results provide a theoretical reference for the assessment indicator selection of enterprise promotion and help executives better understand the impact of promotion mechanism on enterprises and employees. The application of results can reduce the information asymmetry in promotion incentive, prevent the emergence of adverse selection, and achieve a win-win situation for enterprises and employees.
\end{abstract}

\section{Introduction}

1.1. Research Background. Promotion is an essential organizational process for both management and employees [1]. It mainly refers to the promotion of the staff post, namely, transferring from the old post to another post to take on more responsibilities. The promoted employees should bear greater risk and liability; accordingly, they will have greater power and enjoy better benefits. An excellent promotion system can optimize the distribution of human resources and bring benefits to the enterprise.

At present, some scholars [2] in Japan have carried out empirical research: in many large enterprises in Japan, employees prefer to get position promotion rather than a salary increase, that is, the promotion of position can make an employee get more incentive than a salary increase. Many large enterprises in China are similar to those in Japan. Particularly, some state-owned enterprises are owned by the state, and their executives usually have the dual identities of government officials and entrepreneurs ([3], even they are more like officials than professional managers [4]. At the same time, as the salaries of executives in state-owned enterprises are constantly transparent and standardized, employees in state-owned enterprises will pay more attention to the administrative rights and hidden benefits brought by senior positions, which will also make promotion a very important incentive for employees.

In fact, when considering the reasons for promotion, in addition to the dimension of output or performance, there are some employees' demographic characteristic factors that may affect the promotion. Generally speaking, demographic characteristics are not obtained through employees' hard work in an enterprise but exist in employees objectively. Demographic characteristic factors cannot represent employees' subjective ability improvement after they join the work and are very easy to identify, such as gender, age, length of service, and preemployment education. In many large enterprises, especially some of the large state-owned enterprises in China, the output or performance is not directly proportional to individual promotion; some demographic characteristic factors may play a role in promotion. When studying the promotion of officials in China (the 
promotion of state-owned enterprises is similar to the officials), some scholars (Rongrong [5]) analyzed the promotion data of some officials in China from 1990 to 2013 and found that some demographic characteristic factors, such as education level, have a direct impact on promotion. In addition, some studies (Shisong [6]) have also shown that gender is highly correlated with promotion in large state-owned enterprises in China.

Whether demographic characteristic factors have an effect on promotion in large state-owned enterprises is a very important question. Because employees may feel that promotion through demographic characteristics is unfair [7], the fairness of promotion can lead to different incentives for employees. Therefore, in order to improve the objectivity of the research, the factors influencing the promotion can be extended; some demographic characteristic factors can be added to the promotion study as independent variables.

Besides the correlation research between demographic characteristics and promotion, how to use the basic human resource data to make verifiable generalization and prediction of the prospect and characteristics of employee promotion is a difficult problem that many enterprises and consulting institutions have paid extensive attention to. The data mining method [8] can be adopted to find potential knowledge and patterns from a large amount of data, which can enhance the informationization and intelligence of human resource management, so as to effectively solve such problems. Algorithms such as the decision tree, the random forest, and the artificial neural network can be used to discover knowledge and patterns, making intelligent predictions. At present, relevant scholars have used data mining algorithms to study the influence that the joint effect of different factors has on promotion. For example, the C4.5 decision tree algorithm in classification is employed to find the characteristics and rules of employee promotion and to predict the controllable accuracy of employee promotion (Hamidah [9]). In addition, few researches have explored the pattern and rule of employee promotion by using data mining methods, especially the research based on the demographic characteristic factors as input.

Furthermore, game theory also plays an important role in the study of employee promotion. The representative study researches the incentive and cooperation of officials in the promotion game with the promotion championship model (Li'an [10]). However, the promotion game model studied by many scholars at present is still mainly based on the linear relationship between the subjective variables of employees' effort or output and promotion [11], and the game analysis is carried out according to different situations [12]. These game studies rarely consider the role of other objective factors in promotion. In fact, different managers may adopt different assessment forms in the process of employee promotion. For example, the assessment method mainly relies on performance assessment and is supplemented by age, educational background, and other factors. However, such a detailed performance assessment will increase the economic cost of assessment. Otherwise, in order to reduce the economic cost of assessment, the employee promotion is directly based on objective factors such as educational back- ground, age, and gender. Different promotion assessment methods will have different incentive effects on the employees, so that the promoted employee will create different values in the new position, which will affect the total earnings of the enterprise.

1.2. Research Content. Based on a large amount of human resource data of large Chinese state-owned enterprises, this study used the method of logistic regression and the random forest to analyze and find demographic characteristic factors that affect promotion and then summarized the promotion mode of enterprises. Then, based on the results of data analysis, this study establishes a promotion game model based on the information asymmetry principle between enterprise managers and employees, further analyzes the incentive effect of different promotion assessment mechanisms on promoters in different situations, and also elaborates the total return of enterprises, thus triggering thoughts on the promotion mechanism of enterprises and providing a theoretical basis for enterprises to build a promotion system with balanced resource allocation and the incentive function, so as to create a virtuous circle for the development of enterprises and employees. To be more clear, the study structure is shown in Figure 1.

1.3. The Main Points. In this study, data mining and game theory were used for empirical analysis, and the results showed the following:

(1) Apart from the influence on performance, the age, length of service, gender, and educational background of employees have a strong positive correlation with their promotion. That is to say, in Chinese state-owned enterprises, there are still promotion mechanisms that take the demographic characteristic factors of employees as the main factor

(2) Furthermore, different promotion mechanisms require different costs and have different incentive effects on employees, which will make promoters create different benefits in the new positions and ultimately affect the total benefits of the enterprise

(3) In order to maximize the total benefits of the enterprise, the total incomes of the promoted employee in the new positions should be in direct proportion to the difference of the possible benefits created by the promoted employee under different promotion mechanisms

\section{Demographic Characteristic Factors Related to Promotion}

2.1. Factor Selection of Demographic Characteristics. This study proposes the hypotheses for factors that may affect promotion.

Hypothesis 1. There is a strong correlation between demographic characteristic factors (such as age, length of service, gender, and educational background) and promotion. 


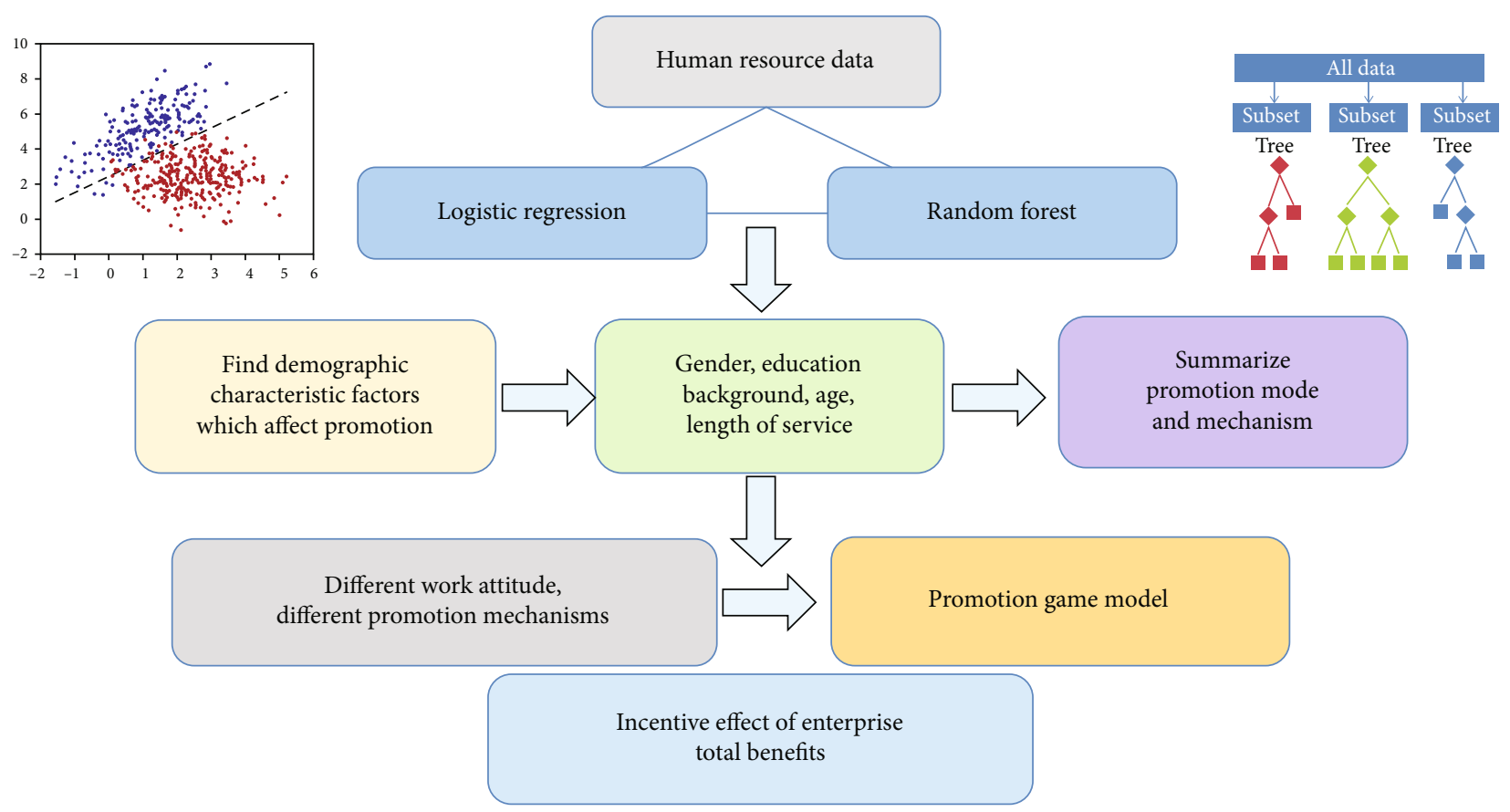

FIgURE 1: Study structure.

It is generally accepted that people with different levels of education have different abilities and qualities. People with higher educational backgrounds have stronger learning and working abilities and have higher probabilities of cultivating excellent talents. Therefore, many enterprises will pay less information screening cost if they choose among those with higher education levels instead of those with lower education levels. Recruitment is like this and so is promotion. Some scholars have confirmed that the education level sent a positive signal to enterprises, that is, individuals have higher cognitive abilities and stronger sense of responsibilities, which is conducive to the performance improvement of enterprises [13]. Some scholars adopted the education level as a formative indicator of human capital and confirmed that the education level had a positive impact on the welfare level [14]. At the same time, the differences in employees' academic qualifications, including those obtained in postwork continuing education, can also directly reflect employees' personal demands which are reflected in their demands for promotion. Highly educated employees have higher demands for promotion. At the same time, their strong abilities and low training cost have become consideration factors for the promotion of employees.

Age and length of service sometimes can be regarded as the measurement of work experience and social capital in enterprises. With the accumulation of employees' age and working age, they will accumulate more work experience and social capital in the enterprise, so that they are more capable of creating benefits for the enterprise and thus getting more promotion space.

Gender is regarded as a reference factor for promotion in many enterprises, and many studies show that although there is no gender difference in salary return for promotion in many jobs, the promotion probability of women is significantly lower than that of men [15]. According to the theory of human capital, due to the influence of fertility, family division of labor, and other reasons, women tend to invest more energy [16]. Since women do more housework, they passively reduce their efforts to work in the enterprise. In this case, their productivity is reduced, and lower performance output than men appears, thus reducing their chances of promotion. At the same time, studies have shown that one of the possible reasons for the low promotion rate of women is that women are significantly more likely to withdraw from the labor market due to family reasons than men. However, enterprises need specific human capital investment before the promotion of employees, which will reduce the rate of return on investment of women in the workplace and thus lower the value of training women [17].

2.2. Data Analysis. This study takes the human resource data of a large state-owned enterprise in China as an example for analysis. The data directly derived from the employee management system of an enterprise through project cooperation; the employee management system records the employees' information objectively and updates the data in real time, which excludes the interference of many subjective factors. We did data cleansing to the original data, including data integration and construction of useful dimensions, to make the whole data tidy and practical.

In all, more than 6,500 pieces of data were analyzed here. The main data dimensions adopted in this study include the age of employees, length of service in the 
enterprise, gender, and education level based on the above analysis; among them, the education level is divided into the highest degree and the first degree. The highest degree is the final degree obtained by employees, which can reflect their knowledge reserve. The first degree generally refers to the degree obtained through the first curricula education accepted after the national college entrance examination. Many Chinese enterprises believe that the first degree can also identify the basic quality and learning ability of an employee. The target dimension is promotion; whether to be promoted is based on the promotion to the middle management level of the enterprise as the threshold, because when taking the middle management position in the enterprise, people will have a larger space to exercise management power independently and give play to personal ability.

In the data sample, the ratio between the nonpromoted and the promoted employees is $1: 9$, that is, there is a very common problem in the study of promotion data: the number of the nonpromoted is much higher than that of the promoted. If promotion is taken as the output, the serious imbalance of dimension value will affect the objectivity and accuracy of data mining results.

In this study, the $k$-means clustering method [18] is adopted to try to solve this problem. A large number of nonpromoted employees' data were analyzed by clustering that based on the partition method, the highest similarity within each cluster and the lowest similarity between clusters could be ensured. Thus, random selection in proportion in each cluster can effectively regulate the data of the nonpromoted employee and finally make it similar to the total data of the promoted employee.

For the convenience of follow-up research, some discrete dimensions' partitioning and assignment should be set to ensure the accuracy of data analysis, as shown in Table 1.

Then, the age of promoters was analyzed, as shown in Figure 2.

Figure 2 shows most promotions occur between the ages of 40 and 50, and 46-48 is the most likely age to be promoted. In Chinese state-owned enterprises, human capital is quite important, which will become higher and higher with the accumulation of time. A common phenomenon in stateowned enterprises is that midlevel leaders are mostly elder employees. Therefore, according to the principle that employees retire at 60 , it is reasonable for employees to break through the threshold of promotion to leadership at around 46 .

Then, the promoters' length of service was compared, as shown in Figure 3.

Figure 3 shows most promotions occur almost between the length of service of 20-28 years; like the age of promotion above, this phenomenon is still the cause of human capital accumulation. Then, the relationship between gender and promotion was analyzed, as shown in Figure 4.

From Figure 4, we can find male employees are promoted at a significantly higher rate than female employees. Then, the relationship between first degree and promotion was analyzed, as shown in Figure 5.

From Figure 5, we can find the proportion of employees with a higher first degree is significantly higher than that of
TABLE 1: Dimension value partitioning and assignment.

\begin{tabular}{lcc}
\hline Dimension & Dimension value partitioning & Assignment \\
\hline \multirow{2}{*}{ First degree } & Below bachelor degree & 0 \\
& Bachelor degree or above & 1 \\
Highest degree & Below bachelor degree & 0 \\
& Bachelor degree & 1 \\
Gender & Master degree or above & 2 \\
\multirow{3}{*}{ Promotion or not } & Female & 0 \\
& Male & 1 \\
& Nonpromoted & 0 \\
\hline
\end{tabular}

employees with a lower first degree. Then, the relationship between highest degree and promotion was analyzed, as shown in Figure 6.

From Figure 6, we can find the higher the employee's highest degree, the more likely he or she is to be promoted.

Then, by comparing the relationship synthetically between different dimensions and the target dimension, Figures 7 and 8 can be obtained.

Multidimensional scatter plot (a) and multidimensional scatter plot (b) are, under the condition of first degree $=0$ and first degree $=1$, the relationship between age ( $x$ axis), length of service ( $y$ axis), highest degree (big circle $=2$, middle circle $=1$, and small circle $=0)$, gender $($ square $=1$, circle $=0)$, and promotion ( $\mathrm{red}=1$, blue $=0)$. It can be seen that with the increase of age and length of service, the number of promoted people is increasing. The higher the degree, the more people are promoted, and men are promoted far more than women. In addition, through the comparison of the two figures, it can be seen that the higher the first degree, the higher the possibility of promotion.

After that, in this study, there are only two dimension values in the target dimension, so we can use a logistic regression model to analyze the correlation between promotion and factors including age, length of service in the enterprise, gender, the first degree, and the highest degree. The method of logical regression is suitable for the classification of discrete values in the target dimension, and the calculated regression coefficients can be used for correlation analysis between different variables. The maximum likelihood method is a suitable method to estimate all coefficients in logistic regression. After calculation, the fitting information of logistic regression is shown in Table 2.

In the model fitting information table, the significance level value in the last column is less than 0.05 , indicating that the model has statistical significance and has passed the test. In addition, its pseudo- $r$-square table is shown in Table 3.

In the pseudo- $r$-square table, the three pseudo- $r$-square values listed in turn are all low, with a maximum of 0.325 , indicating that the model has a general explanatory degree for the variation of the original variable, and some information cannot be explained, so the fitting degree is not very outstanding. 


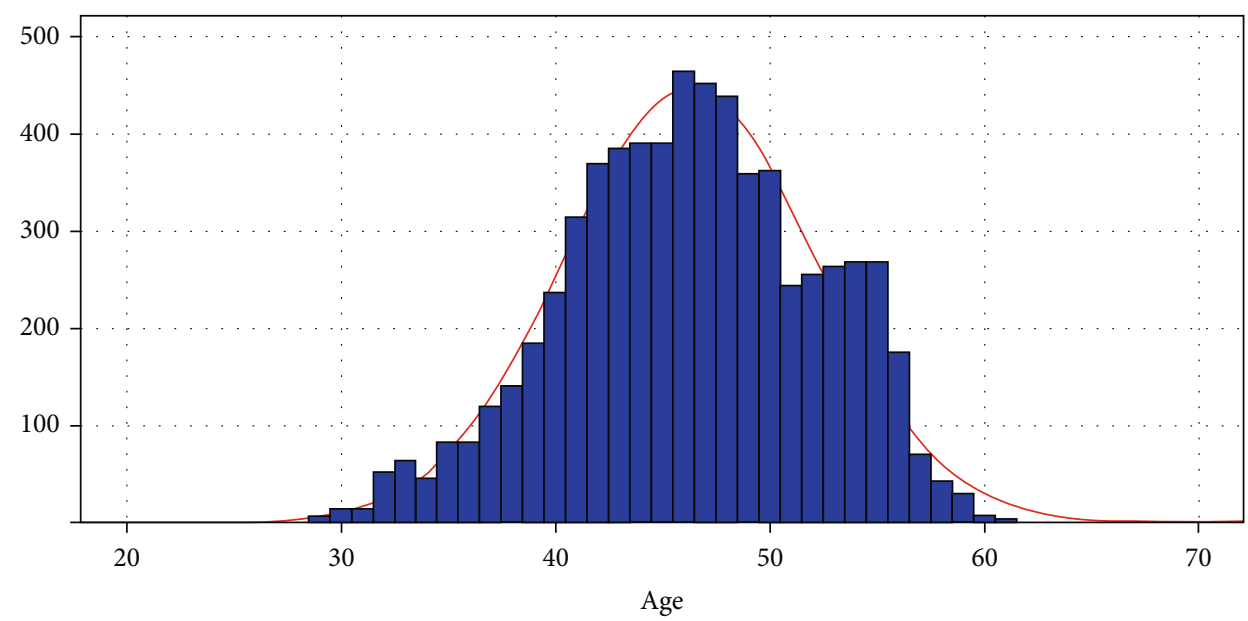

Figure 2: Age distribution of promoters.

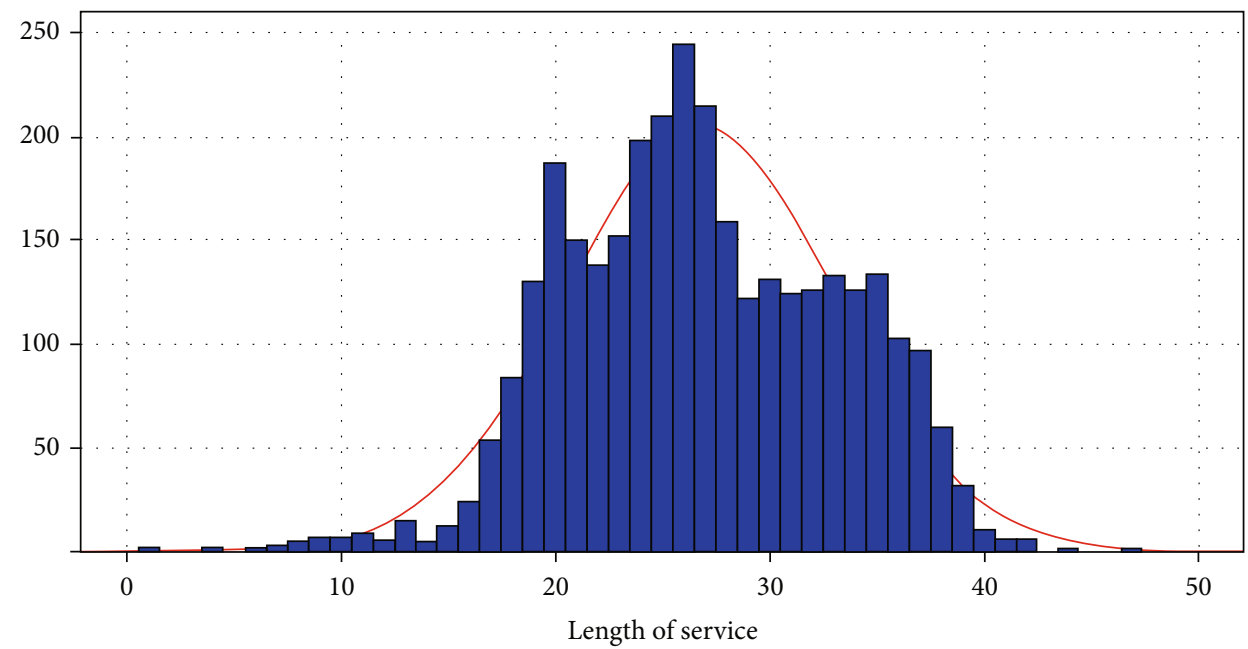

FIGURE 3: Length of service distribution of promoters.

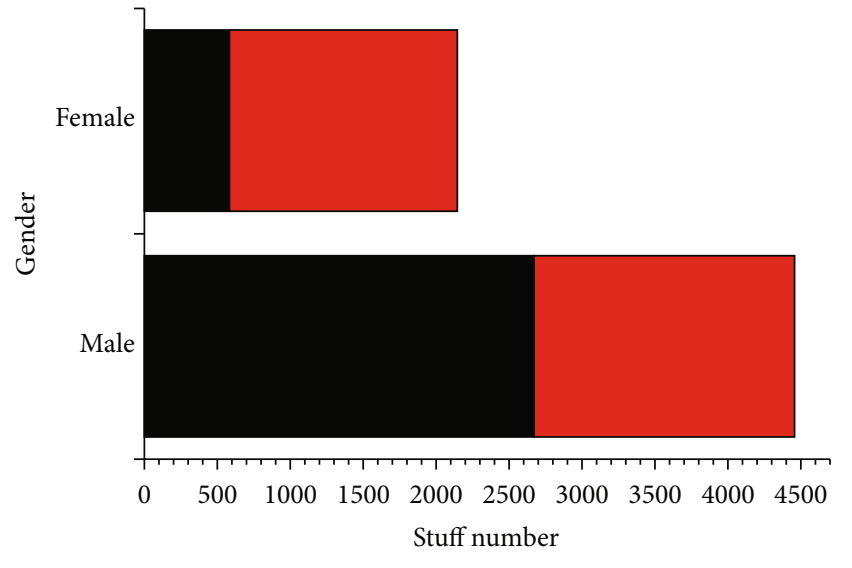

Nonpromoted

Promoted

Figure 4: The relationship between gender and promotion.
The parameter estimation of the regression model is shown in Table 4.

According to the significance test in column 7 of the table, it can be seen that the significance levels are all less than 0.05 , indicating that the corresponding independent variables have a significant impact on the dependent variables. As can be seen from the $B$ value in column 2, the length of service and age are positively correlated with promotion. If "the first degree= below bachelor degree" is set as the reference group, "the first degree=bachelor degree or above" is positively correlated with promotion. In other words, people with higher first degrees are more likely to get promotion space, while those with lower first degrees are the opposite. If "gender =female" is set as the reference group, "gender $=$ male" is positively correlated with promotion, that is, men are relatively easy to get promotion opportunities, while women are on the contrary. If "the highest degree = below bachelor degree" is set as the reference group, "the highest degree=bachelor degree" and "the highest degree $=$ master degree or above" are both 


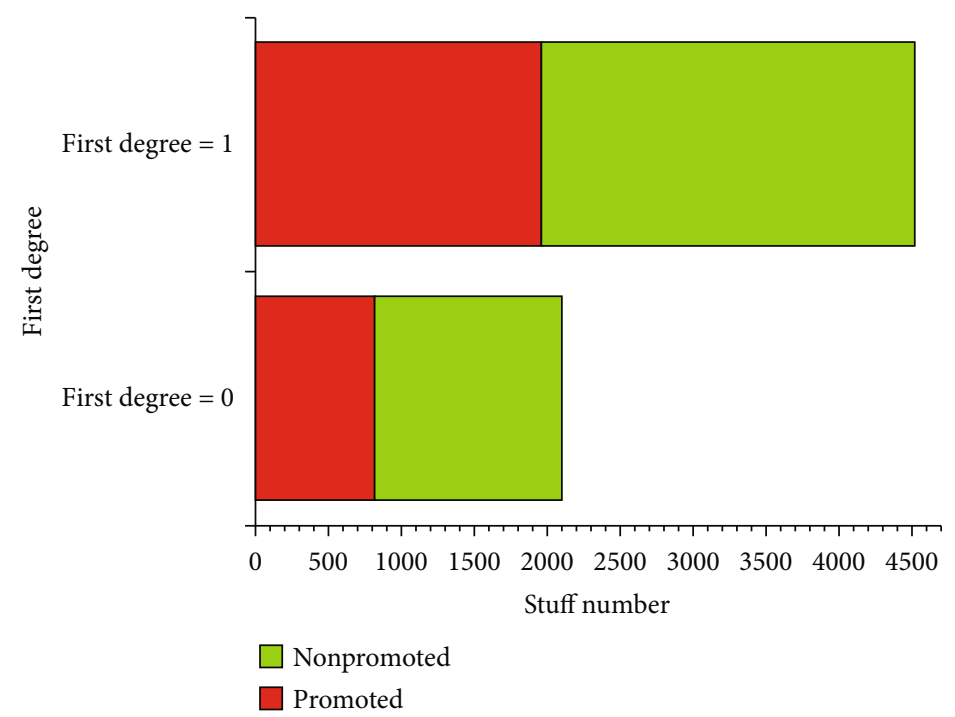

FIgURE 5: The relationship between first degree and promotion.

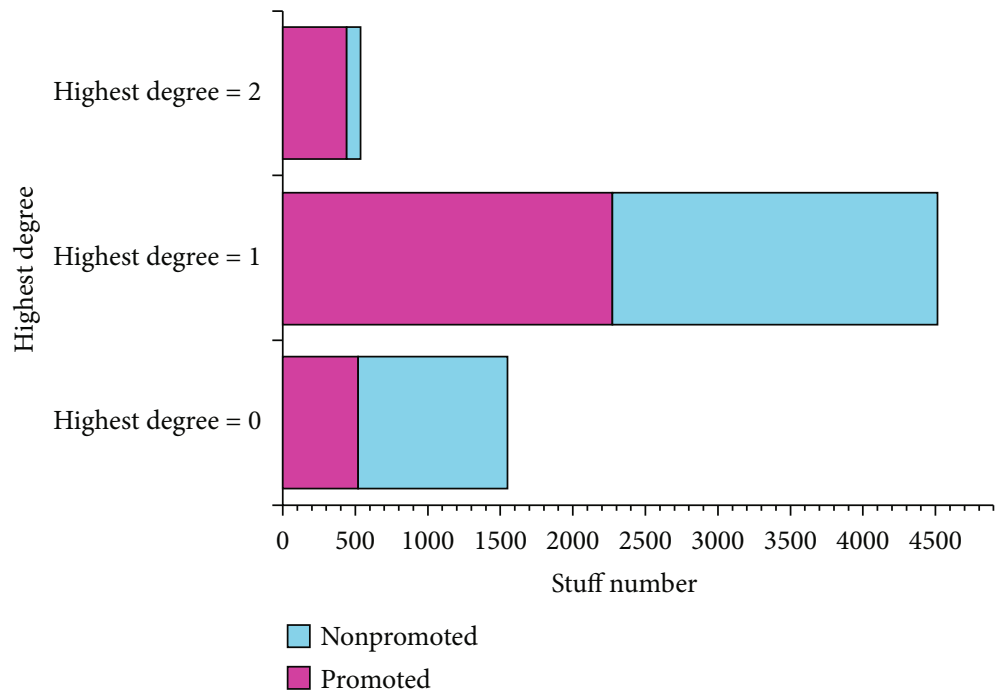

FIGURE 6: The relationship between highest degree and promotion.

positively correlated with promotion; as it is shown above, the higher the highest degree is, the more likely one is to be promoted. The promotion equation based on the logistic regression model is as follows:

$$
\begin{aligned}
(\text { Promotion }=1)= & 0.03936 * \text { length of service } \\
& +0.1024 * \text { age }+0.4417 \\
& *(\text { first degree }=\text { bachelor degree or above }) \\
& +1.252 *(\text { gender }=\text { male })+2.749 \\
& *(\text { the highest degree }=\text { master degree or above }) \\
& +1.131 *(\text { the highest degree }=\text { bachelor degree }) \\
& +-7.751 .
\end{aligned}
$$

In this study, the data set is divided into the training set and the test set, and the logistic regression model obtained from the training set above is brought into the test set for precision verification. The accuracy is $78.9 \%$ which is within a reasonable range. Therefore, Hypothesis 1 is verified.

Furthermore, in order to study the comprehensive effect of the above factors on promotion and improve the precision of data mining results, this study used the methods of C4.5 decision tree, C5.0 decision tree, the support vector machine (SVM), and random forest (RF) to analyze data. The random forest algorithm has good performance for solving classification problems, its training speed is faster, and the result is more accurate. Meanwhile, because the target dimension value is discrete, we can also use the method of decision tree for classification analysis, while C4.5 and C5.0 are typical decision tree algorithms. At the same time, under the existing amount of data, SVM can also be better applied to classification problems and have a strong learning ability. 


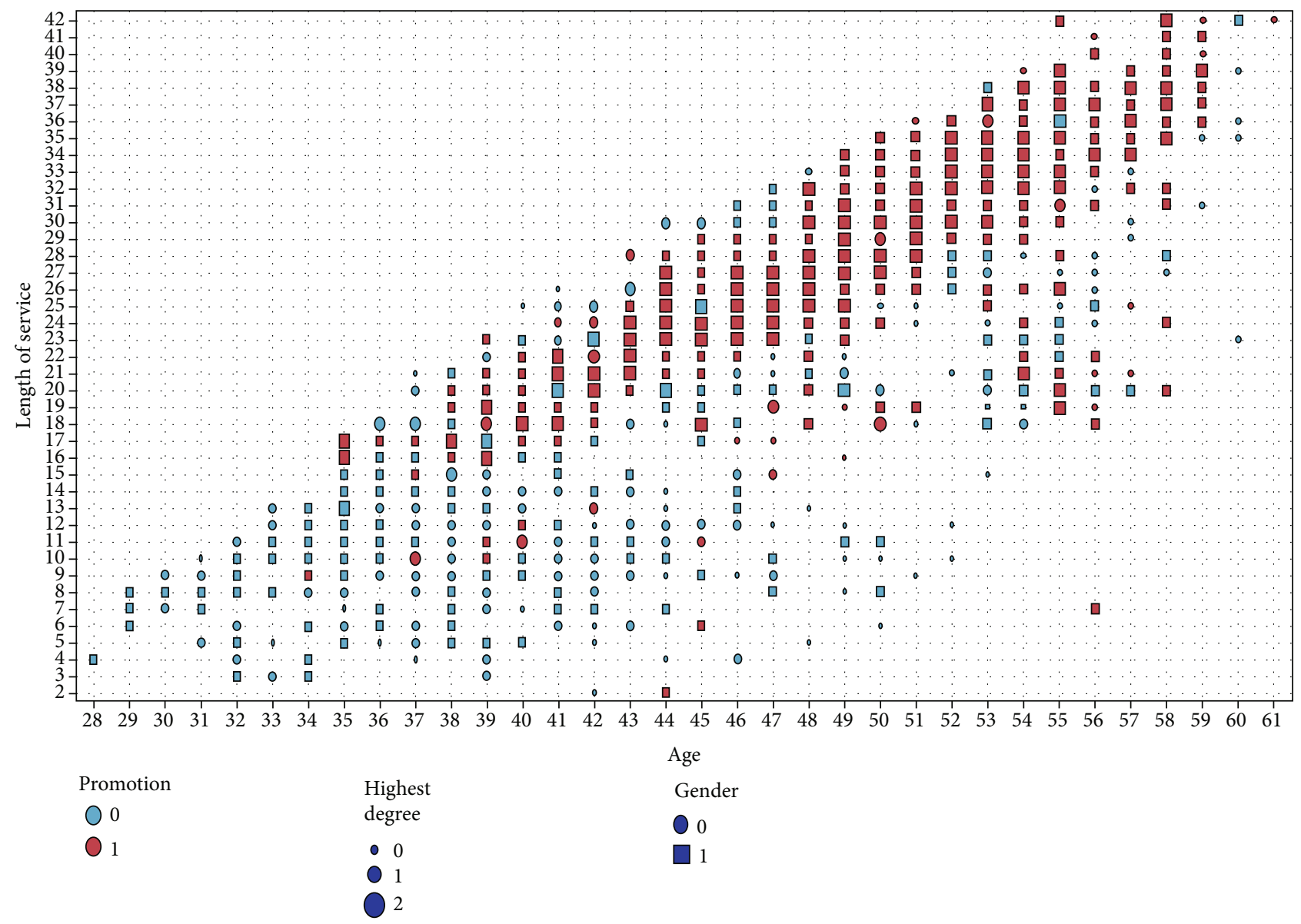

FIgURE 7: Multidimensional scatter plot (a).

The employee's age, length of service in the enterprise, gender, the first degree, and the highest degree are taken as input, and whether they are promoted is taken as output. In order to increase the objectivity of the conclusion, we selected different sample sizes for algorithm analysis. Through the training of the models, the results are obtained and the accuracy is checked in the test set, as shown in Table 5.

As can be seen from Table 5, the random forest algorithm is the most accurate in this study. Because random forest is a classifier that contains multiple decision trees, and its output category is determined by the majority of the output category of each tree [19]. Compared with the traditional decision tree algorithm, the analysis of the random forest algorithm is more accurate and can prevent overfitting. The algorithm works as follows.

Firstly, the bootstrap sampling technique is used to extract $N$ training sets from the original samples. Secondly, the algorithm constructs the CART decision tree for each training set and generates a forest composed of $N$ CART decision trees. Thirdly, the algorithm randomly selects $m$ ( $m<M)$ feature variables from all $M$ feature variables. According to the principle of the minimum Gini coefficient, the characteristics of the training set are selected and internal node branches are carried out. Finally, the output of $N$ decision trees is set for voting, and the class with the most votes is taken as the decision result of the random forest.

In the random forest algorithm, the Gini coefficient is used to measure the effect of feature segmentation in node segmentation. Suppose that there are $K$ classes in sample $D$, then its Gini coefficient is

$$
\operatorname{Gini}(D)=1-\sum_{k=1}^{K}\left(\frac{C_{k}}{D}\right)^{2}
$$

In the above formula, $C_{k}$ is a subset of the $k$ class in $D$, and $K$ is the number of classes. If after a partition, the sample set $D$ is divided into $m$ parts, $D_{1}, D_{2} \cdots D_{m}$, the Gini coefficient of this partition is

$\operatorname{Gini}_{\text {split }}(D)=\frac{\left|D_{1}\right|}{|D|} \operatorname{Gini}\left(D_{1}\right)+\frac{\left|D_{2}\right|}{|D|} \operatorname{Gini}\left(D_{2}\right) \cdots+\frac{\left|D_{m}\right|}{|D|} \operatorname{Gini}\left(D_{m}\right)$.

The Gini coefficient is inversely proportional to the segmentation effect. The value of the Gini coefficient can be calculated to rank the importance of all features. The larger the value is, the more important the feature will be. 


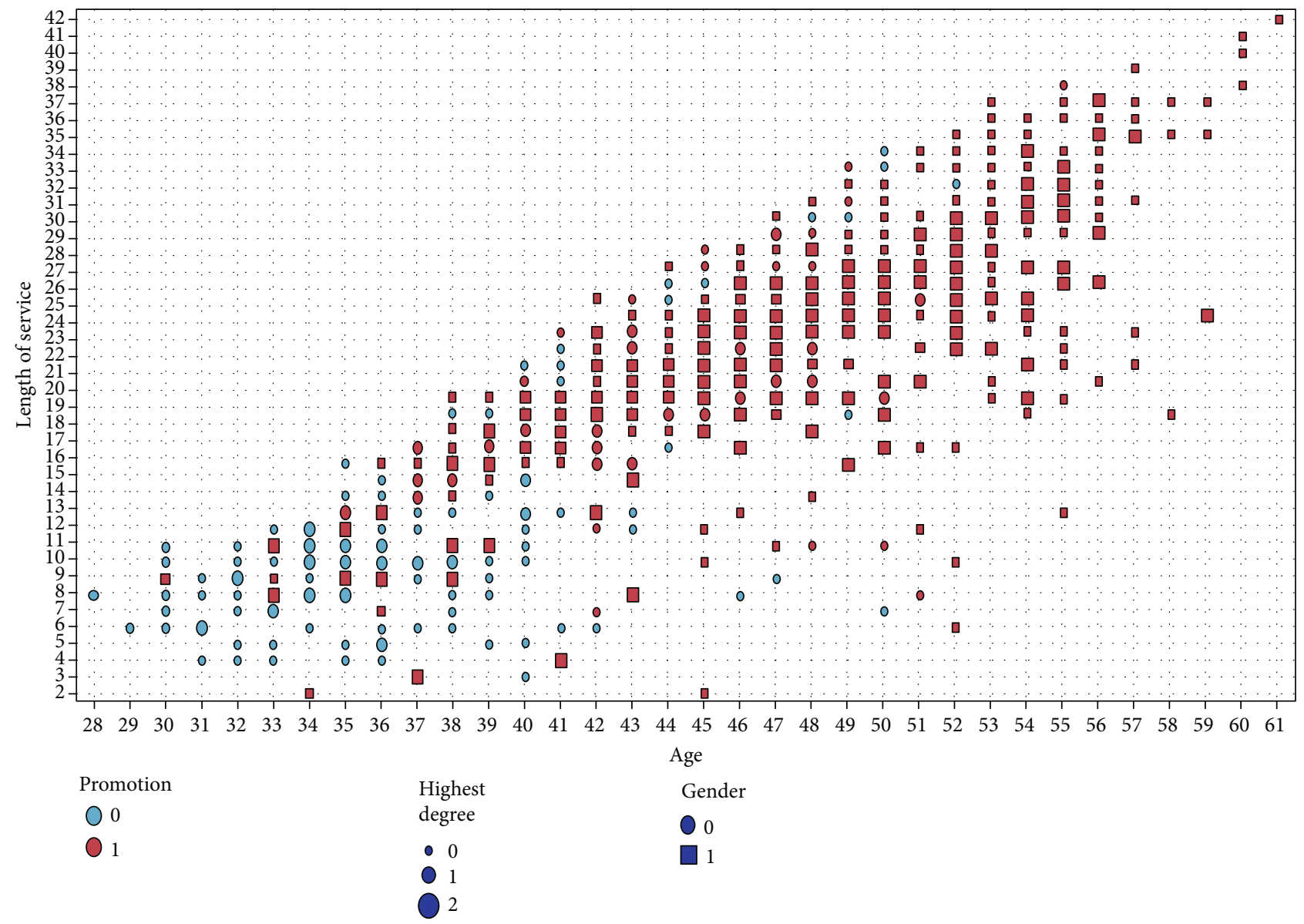

FIgURE 8: Multidimensional scatter plot (b).

TABLE 2: Fitting information.

\begin{tabular}{lcccc}
\hline \multirow{2}{*}{ Model } & Model fitting criteria & \multicolumn{3}{c}{ Likelihood-ratio test } \\
& $-2 \log$ likelihood & Chi-square & df & Sig. \\
\hline Intercept only & 5019.676 & & & \\
Final & 3187.831 & 1831.845 & 6 & 0.000 \\
\hline
\end{tabular}

TABle 3: Pseudo-r-square.

\begin{tabular}{ll}
\hline Cox and Snell & 0.244 \\
Nagelkerke & 0.325 \\
McFadden & 0.202 \\
\hline
\end{tabular}

In this study, the promotion model of an employee in an enterprise can be summarized through the random forest model by the steps above.

The male employees with the first degree and the highest degree of bachelor degrees or above and at the age from 41 to 52 are most likely to be promoted to middle-level leadership in the enterprise.

The accuracy of this model is higher than the previous logistic regression model. The result also shows demographic characteristics are helpful for promotion.

\section{Research on the Promotion Mechanism Based on Game Theory}

3.1. The Influence of Different Promotion Mechanisms on Employees. Based on the above research, it can be seen that except the work performance or the level of effort, demographic characteristic factors may also become an important condition for enterprises to select talents for promotion. Based on the above data analysis and the field survey of enterprises, the study shows that when employees are promoted, large enterprises have different promotion mechanisms, which mainly include the following:

(1) Comprehensively and reasonably investigating employees' contribution, performance, effort, working status, and so on, making the best choice

(2) Promotion mainly based on demographic characteristic factors, such as the educational background, age, and gender

For the first kind, the enterprise may need a high screening cost for promotion, because the enterprise is essentially a teamwork production; the products are produced by team members' work together, but as a result of the existence of information asymmetry, it is difficult to depict each 
TABle 4: Parameter estimation of the regression model.

\begin{tabular}{|c|c|c|c|c|c|c|c|c|c|}
\hline \multirow[t]{2}{*}{ Job level } & & \multirow[t]{2}{*}{$B$} & \multirow[t]{2}{*}{ Std. error } & \multirow[t]{2}{*}{ Wald } & \multirow[t]{2}{*}{ df } & \multirow[t]{2}{*}{ Sig. } & \multirow[t]{2}{*}{$\operatorname{Exp}(B)$} & \multicolumn{2}{|c|}{$\begin{array}{l}\text { 95\% confidence interval for } \\
\qquad \operatorname{Exp}(B)\end{array}$} \\
\hline & & & & & & & & Lower bound & Upper bound \\
\hline \multirow{10}{*}{ Promotion } & Intercept & -7.751 & 0.353 & 482.015 & 1 & 0.000 & & & \\
\hline & Length of service & 0.039 & 0.009 & 20.729 & 1 & 0.000 & 1.040 & 1.023 & 1.058 \\
\hline & Age & 0.102 & 0.011 & 92.501 & 1 & 0.000 & 1.108 & 1.085 & 1.131 \\
\hline & First degree $=$ below bachelor degree & $0(\mathrm{~b})$ & . & . & 0 & . & . & . & . \\
\hline & First degree $=$ bachelor degree or above & 0.442 & 0.068 & 42.152 & 1 & 0.000 & 1.555 & 1.361 & 1.777 \\
\hline & Gender $=$ female & $0(\mathrm{~b})$ & . & . & 0 & . & . & . & . \\
\hline & Gender $=$ male & 1.252 & 0.064 & 381.902 & 1 & 0.000 & 3.498 & 3.085 & 3.967 \\
\hline & Highest degree $=$ below bachelor degree & $0(\mathrm{~b})$ & . & . & 0 & . & . & . & . \\
\hline & Highest degree = bachelor degree & 1.131 & 0.078 & 211.468 & 1 & 0.000 & 3.097 & 2.660 & 3.607 \\
\hline & Highest degree $=$ master degree or above & 2.749 & 0.148 & 343.395 & 1 & 0.000 & 15.627 & 11.684 & 20.900 \\
\hline
\end{tabular}

TABLE 5: Comparison of algorithm accuracy.

\begin{tabular}{|c|c|c|c|c|}
\hline Algorithm & C4.5 & C5.0 & SVM & RF \\
\hline Accuracy ( $100 \%$ of total sample size) & $75.3 \%$ & $78.2 \%$ & $77.4 \%$ & $83.4 \%$ \\
\hline Accuracy ( $80 \%$ of total sample size) & $74.4 \%$ & $77.6 \%$ & $75.5 \%$ & $82.8 \%$ \\
\hline Accuracy ( $60 \%$ of total sample size) & $74 \%$ & $75.8 \%$ & $75.2 \%$ & $81.5 \%$ \\
\hline Accuracy ( $40 \%$ of total sample size) & $72.2 \%$ & $74.5 \%$ & $73.7 \%$ & $81 \%$ \\
\hline Accuracy ( $20 \%$ of total sample size) & $71 \%$ & $73.6 \%$ & $72.8 \%$ & $80.3 \%$ \\
\hline
\end{tabular}

member's individual contribution accurately; if the enterprise does so, the cost of supervision and identification of marginal output will increase significantly. Therefore, it becomes very difficult or even impossible to determine promotion candidates based on marginal output and marginal contribution.

However, the first promotion mechanisms will make employees feel fair, which will stimulate the employees' enthusiasm and improve the income of the enterprise.

For the second kind, although the screening cost of the enterprise is low, employees will feel unfair and have negative emotions, which will reduce the work efficiency and the income of the enterprise. Some scholars [7] found that employees would compare their promotion approaches with others and judge the fairness of promotion. Most employees believe that factors such as work performance could serve as the important basis for promotion. Other scholars [20] found through research that the higher the fairness of promotion perceived by employees is, the harder they will work, thus bringing more profits to the enterprise.

Therefore, the selection of different employee promotion mechanisms will have an impact on the overall resource allocation and revenue of enterprises. If there are problems in the promotion mechanism, such as taking the demographic characteristics of employees as the main factor of promotion, employees will think that the enterprise lacks the fairness of promotion, which will have a negative impact on employees' work enthusiasm. In this way, employees who are promoted by demographic characteristics rather than performance will not be inclined to work hard in their new positions even if they are paid more, because they will think such demographic characteristic factors will help them continue to be promoted, and the higher salary is deserved after promotion. Therefore, this promotion mechanism does not generate positive incentives for employees and eventually bring losses to the enterprise. In some enterprises, managers do not have rigid and clear promotion indicators and systems but promote employees through decision-making meetings or subjective decisions of managers; that is to say, the two promotion mechanisms may exist at the same time, or promotion in the two mechanisms left and right sway, such enterprises are most prone to the above problem, resulting in the loss of corporate interests.

\subsection{Promotion Game Strategy Based on the Maximization of} Enterprise Benefit. In the employee promotion, there is a problem of information asymmetry that refers to the information that some participants have in one aspect but others lack or have no complete information (Weiying [21]). It is an important factor that affects the efficiency of transactions, especially for human capital transactions. Therefore, the game theory of information economics has been introduced into the promotion problem.

Based on the choice of different promotion mechanisms, there is an important game between managers and promoted employees. In large state-owned enterprises, many promotion decisions are based on managers' subjective decision research, so there may be included different promotion factors, such as the employee's performance and the 
Table 6: Promotion game matrix.

\begin{tabular}{ccc}
\hline & $Y$ & $N$ \\
\hline$T$ & $0,-h$ & $w, v_{2}-w$ \\
$S$ & $w-g, v_{1}-w-h$ & $w-g, v_{1}-w$ \\
\hline
\end{tabular}

TABLe 7: Nash equilibrium.

\begin{tabular}{ccc}
\hline & $Y$ & $N$ \\
\hline$T$ & $0,-h$ & $\underline{w}, \underline{v_{2}-w}$ \\
$S$ & $\underline{w-g}, v_{1}-w-h$ & $w-g, \underline{v_{1}-w}$ \\
\hline
\end{tabular}

TABle 8: No Nash equilibrium solution.

\begin{tabular}{ccc}
\hline & $Y$ & $N$ \\
\hline$T$ & $0, \underline{-h}$ & $\underline{w}, v_{2}-w$ \\
$S$ & $\underline{w-g}, v_{1}-w-h$ & $w-g, \underline{v_{1}-w}$ \\
\hline
\end{tabular}

demographic characteristic factors; then, different types of incentive are produced in the promotion, so how to use the method of game theory to gain optimal benefits for enterprise is a problem worthy of study.

In this study, we focus on the enterprises where the two different promotion mechanisms exist. Based on the consideration of enterprises' overall benefits, we believe that the benefits provided by the enterprise for promoted employees are not the higher the better; high benefits do not necessarily produce high incentives, so the benefits should be related to those created by the employees in different working attitudes and thus put forward the following assumptions:

Hypothesis 2. Different promotion mechanisms will generate different incentives for employees. If the overall benefits of the enterprise are to be optimal, the benefits provided by the enterprise for promoted employees should be in direct proportion to the difference of the benefits brought to the enterprise by the promoted employees under different incentives.

In order to prove the rationality of this hypothesis, this study is based on the principal-agent model of traditional game research [22]. Here, the client is the enterprise manager and decision maker, and the agent is the employee waiting to be promoted. There are two strategic spaces for enterprise managers as follows:

First, enterprise managers should investigate the performance, effort, and working status of employees comprehensively and reasonably so as to screen the promotion of employees, set as $Y$.

Second, enterprise managers screen the promotion of employees mainly based on demographic characteristics, set as $N$.

The promoted employees are also featured with two different strategic spaces before promotion: hard work for performance or perfunctory work, when they are set as $S$ and $T$, respectively. In addition, we suppose the following:
(1) Compared with strategy $N$, the cost of enterprise screening by strategy $Y$ is $h$

(2) The overall welfare of the promoted employees after promotion is $w$, and $w>h$

(3) Compared with strategy $T$, all efforts put by employees into promotion using strategy $S$ are set as $g$, and $w>g$

(4) The income created in the new position by employees who are positively motivated in promotion is $v_{1}$. If the enterprise can operate normally, the income is expressed as $v_{1}>w$

(5) The income created in the new position by employees who are not motivated in promotion is $v_{2}$

It is assumed that the employees waiting for promotion have certain human capital, such as long working years, the gender of males, and advanced education, but the promotion strategy adopted by enterprise managers is not completely known by employees.

If the enterprise adopts strategy $Y$ for screening, and the working state of employees is $T$, the employees will not be promoted, and their promotion utility is 0 . In this case, as the enterprise has lost some screening costs, it gained $-h$.

If the enterprise adopts strategy $Y$ for screening, and the working state of the employees is $S$, their promotion utility will be $w-g$. Besides, since strategy $Y$ has positive incentives for the employee, the enterprise will gain $v_{1}-w-h$ after the promotion.

If the enterprise adopts strategy $N$ for screening, and the working state of the employee is $T$, the employee will also be promoted by demographic characteristic factors, since the employee fails to make corresponding work effort $g$, and the promotion utility of the employee is $w$. However, as employees do not get positive incentives and the company does not suffer from the loss of screening cost $h$, the enterprise gains $v_{2}-w$ after the promotion.

If the enterprise adopts strategy $N$ for screening, and the working state of the employee is $S$, the promotion utility of employees is $w-g$, since the employees really worked hard and got the promotion, so employees will mistakenly believe that they are promoted through hard work. Therefore, they will still create $v_{1}$ benefits in the new position, and furthermore, the income obtained by the enterprise is $v_{1}-w$.

To sum up, the following game matrix is shown in Table 6 .

When $v_{2}-w \geqq-h$, that is, $v_{2} \geqq w-h$, the problem can be expressed as the following matrix shown in Table 7 , where there is a Nash equilibrium solution of pure strategy $\left(w, v_{2}-\mathrm{w}\right)$.

However, there is a situation that can be commonly seen. In other words, $v_{2}$ without positive excitation will be extremely small, and then, $v_{2}<w-h$ occurs, as shown in Table 8.

There is no Nash equilibrium solution of pure strategy, and therefore, we need to study mixed strategies of the Nash equilibrium. Suppose the probability of employees adopting strategy $T$ is $x$, then the probability of adopting strategy $S$ 
and enterprise adopting strategy $Y$ is $1-x$ and $y$ accordingly. In this case, the probability of adopting strategy $N$ is $1-y$.

Then, the expected profit of the enterprise is

$$
\begin{aligned}
\mu_{1}\left(\sigma_{1}, \sigma_{2}\right)= & y\left(-x * h+(1-x)\left(v_{1}-w-h\right)\right) \\
& +(1-y)\left(x\left(v_{2}-w\right)+(1-x)\left(v_{1}-w\right)\right)
\end{aligned}
$$

According to the definition of the Nash equilibrium, given the employees' mixed strategy $(x, 1-x)$, the value of $y$ is sought to maximize $\mu_{1}\left(\sigma_{1}, \sigma_{2}\right)$. Therefore, in the equation mentioned above, take the partial derivative to $y$ and set the equation as 0 . Then, we can get $x=h /\left(w-v_{2}\right)$.

Similarly, employees' expected profits after promotion are

$$
\begin{aligned}
\mu_{2}\left(\sigma_{1}, \sigma_{2}\right)= & x(0 * y+w(1-y))+(1-x)((w-g) y \\
& +(w-g)(1-y)) .
\end{aligned}
$$

According to the definition of the Nash equilibrium, given the enterprise's mixed strategy $(y, 1-y)$, the value of $x$ is sought to maximize $\mu_{2}\left(\sigma_{1}, \sigma_{2}\right)$. Therefore, in the above equation, take the partial derivative to $x$ and set the equation as 0 . Thus, we can get $y=g / w$.

Therefore, the Nash equilibrium solution of the mixed strategy for this promotion problem is

$$
\left(\frac{h}{w-v_{2}}, 1-\frac{h}{w-v_{2}}\right),\left(\frac{g}{w}, 1-\frac{g}{w}\right) \text {. }
$$

When bringing it into the expected profit of the enterprise, there is

$$
\mu_{1}(\sigma * 1, \sigma * 2)=h \frac{v_{2}-v_{1}}{w-v_{2}}+v_{1}-w
$$

Generally speaking, $v_{1}, v_{2}$, and $h$ are relatively fixed values, while the overall welfare given by enterprises to promoted employees is a variable. Here, take the partial derivative to $w$ and set it as $\mu_{1}\left(\sigma_{1}, \sigma_{2}\right)=0$. We can obtain the following:

$$
\left(w-v_{2}\right)^{2}=h\left(v_{1}-v_{2}\right)
$$

That is,

$$
w=\sqrt{h\left(v_{1}-v_{2}\right)}+v_{2}
$$

or

$$
w=v_{2}-\sqrt{h\left(v_{1}-v_{2}\right)} .
$$

From (10), there is $v_{2}=w+\sqrt{h\left(v_{1}-v_{2}\right)}>w-h$, which contradicts the above condition $v_{2} \leqq w-h$ of mixed strategy of the Nash equilibrium. Therefore, in order to achieve the maximization of enterprises' benefits, enterprises offer benefits to the promoted employees, which should refer to formula (9).
In other words, the total welfare provided by the enterprise for the promoted employees should be in direct proportion to the difference of benefits brought to the enterprise by the promoted employees under different incentives and also in direct proportion to the promotion screening cost of the enterprise. Therefore, Hypothesis 2 is verified.

\section{Discussions and Conclusions}

Overall, this study analyzed the demographic characteristic factors that influence the employee promotion in stateowned enterprises of China based on massive human resource data and conducted empirical research on the factors of gender, age, length of service, and the education level. The logistic regression method was adopted to verify the strong correlation between these factors and the promotion of an employee. At the same time, different classification methods of data mining are used to analyze and summarize the patterns and characteristics of employee promotion in enterprises, which can be used for intelligent and informationized enterprise human resource management.

On this basis, the principal-agent model of game theory is further employed to investigate the impact of different promotion mechanisms on enterprises. The performanceoriented and comprehensive employee promotion mechanism needs high talent screening cost, but it will generate positive incentives for employees, thus creating more benefits for the enterprise. The promotion mechanism based on demographic characteristics needs less screening cost, but it will generate negative incentives for employees, thus reducing the benefits for the enterprise. Therefore, in this study, the conditions for enterprises were analyzed to obtain the maximum benefits when the enterprise chooses different promotion mechanisms and employees choose different work attitudes.

In theory, this paper provides a theoretical basis for whether there are factors other than performance in employee promotion. That is, employees' demographic characteristics have a great influence on promotion in large stateowned enterprises in China, which can provide a theoretical reference for the assessment indicator selection of enterprise promotion. Secondly, this paper helps the executives of stateowned enterprises better understand the impact of employee promotion on enterprises and the significance of improving promotion mechanism.

In terms of managerial implications, the paper finds out the characteristics of employees promoted in state-owned enterprises in China through the method of data mining, which has a certain guiding role for state-owned enterprises to summarize the law of employee promotion, carrying out informationalized talent management and talent development. In addition, our conclusions can provide a practical basis for executives of state-owned enterprises to reduce their labor costs and to enhance the allocation of human resources. The executives of state-owned enterprises can take this study as a reference to provide welfare benefits for promoters, so as to ensure the maximization of profits of enterprises under the influence of different promotion mechanisms. The application of conclusion also can reduce the problem 
of information asymmetry in promotion incentive, prevent the emergence of adverse selection, and achieve a win-win situation for enterprises and employees.

However, data mining methods of our study have some limitations. First, the dimension values of some dimensions are not very average, for example, the proportion of men and women is not quite equal in the gender dimension, which will have a certain impact on the analysis results. Second, since data of employee performance or output are difficult to measure and obtain, the disturbance lof employee performance on promotion is not excluded when analyzing the influence of demographic characteristics on promotion. In other words, it is necessary to analyze the influence of demographic characteristics on promotion under the circumstance of the employees' same or similar performance level.

In the future research, we will further rationalize the data preprocessing and obtain the data resources that can represent employees' performance through enterprise research, analyze the demographic characteristics of employees at the same level of performance, and deeply study the relationship between demographic characteristic factors and promotion. In addition, we will continue to construct more interesting factors and analyze their correlation with promotion, such as the factors like employees' prepromotion positions and the relationship between promoted employees and senior executives.

\section{Data Availability}

The xls data used to support the findings of this study were supplied by the Talent Assessment Center of China Post under license and so cannot be made freely available. Requests for access to these data should be made to Hao Kou,18810751@qq.com.

\section{Conflicts of Interest}

We declare that we have no conflicts of interest, financial or otherwise, in this work.

\section{References}

[1] J. T. Delaney and M. A. Huselid, "The impact of human resource management practices on perceptions of organizational performance," Academy of Management Journal, vol. 39, no. 4, pp. 949-969, 1996.

[2] K. Takahashi, "Effects of wage and promotion incentives on the motivation levels of Japanese employees," Career Development International, vol. 11, no. 3, pp. 193-203, 2006.

[3] D. Chen, J. B. Kim, O. Z. Li, and S. Liang, "China's closed pyramidal managerial Labor market and the stock price crash risk," The Accounting Review, vol. 93, no. 3, pp. 105-131, 2017.

[4] X. Lu, Y. He, and T. Wu, "Is SOE executives' political promotion incentive a long-term solution," Economic Management Journal, vol. 7, pp. 94-106, 2016.

[5] R. Lin, "How does human capital affect the promotion of officials - based on the promotion process of provincial leaders from 1990 to 2013," Journal of Political Science, vol. 1, pp. 91-105, 2019.
[6] S. Qing, "Gender discrimination in promotion," Management World, vol. 11, pp. 28-38, 2011.

[7] T. A. Beehr, V. N. Nair, D. M. Gudanowski, and M. Such, "Perceptions of reasons for promotion of self and others," Human Relations, vol. 57, no. 4, pp. 413-438, 2016.

[8] C. C. Wu, Y. L. Chen, Y. H. Liu, and X. Y. Yang, "Decision tree induction with a constrained number of leaf nodes," Applied Intelligence, vol. 45, no. 3, pp. 673-685, 2016.

[9] H. Jantan, "Human talent prediction in HRM using C4.5 classification algorithm," International Journal on Computer Science and Engineering, vol. 2, pp. 2526-2534, 2010.

[10] L.'a. Zhou, “The motivation and cooperation of government officials in the promotion game," Economic Research Journal, vol. 6, pp. 33-40, 2004.

[11] M. Chen and X. Chen, "Game analysis of traditional promotion system," East China Economic Management, vol. 9, pp. 94-97, 2005.

[12] Y. Lei and P. Yongjian, "Game analysis of human resource promotion model," Journal of Business Research, vol. 15, pp. 64-65, 2006.

[13] T. W. H. Ng and D. C. Feldman, "Human capital and objective indicators of career success: the mediating effects of cognitive ability and conscientiousness," Journal of Occupational and Organizational Psychology, vol. 83, no. 1, pp. 207-235, 2010.

[14] M. Hayek, C. H. Thomas, M. M. Novicevic, and D. Montalvo, "Contextualizing human capital theory in a non-Western setting: testing the pay-for-performance assumption," Journal of Business Research, vol. 69, no. 2, pp. 928-935, 2016.

[15] F. D. Blau and J. Devaro, "New evidence on gender differences in promotion rates: an empirical analysis of a sample of new hires," Industrial Relations, vol. 46, no. 3, pp. 511-550, 2007.

[16] G. S. Becker, "Human capital, effort, and the sexual division of labor," Journal of Labor Economics, vol. 3, 1, Part 2, pp. S33S58, 1985.

[17] T. Pekkarinen and J. Vartiainen, "Gender differences in promotion on a job ladder: evidence from Finnish metalworkers," Industrial and Labor Relations Review, vol. 59, no. 2, pp. 285-301, 2016.

[18] J. Han and M. Kambe, Data Mining: Concepts and Techniques, Elsevier, Amsterdam, 2011.

[19] L. Breiman, "Random forest," Machine Learning, vol. 45, no. 1, pp. 5-32, 2001.

[20] S. Foley, D. L. Kidder, and G. N. Powell, "The perceived glass ceiling and justice perceptions: an investigation of Hispanic law associates," Journal of Management, vol. 28, no. 4, pp. 471-496, 2016.

[21] W. Zhang, Game Theory and Information Economics, Shanghai people's publishing house, Shanghai, 1996.

[22] J. J. Laffont, The Theory of Incentives the Principal-Agent Model, Princeton University Press, Princeton, 2002. 